Asthma

\section{Non-eosinophilic asthma and the innate immune response}

\section{Ian D Pavord}

\section{Pathological heterogeneity of asthma}

$\mathrm{T}$ he concept that there may be heterogeneity of the underlying pathology of asthma has a long pedigree: 80 years ago, Rackemann ${ }^{1}$ suggested that a subgroup of patients with intrinsic asthma had disease driven by bacterial infection of the upper and lower respiratory tract and the authors of an early postmortem study ${ }^{2}$ were struck by the heterogeneity of lower airway inflammatory response in fatal asthma. However, since then the prevailing view, largely driven by bronchial biopsy studies of limited numbers of patients with relatively mild disease, has been that there are more similarities than differences in the pathology of subtypes of asthma. Thus, asthma is currently viewed as a condition characterised by TH2 cytokinemediated eosinophilic airway mucosal inflammation. ${ }^{3}{ }^{4}$

The development of simple methods to assess airway inflammation non-invasively using induced sputum which are applicable to a wide variety of patients $s^{5}$ has renewed interest in investigation of the pathological heterogeneity of asthma. Using this technique, Turner et $a l^{6}$ unexpectedly found that just under half of 34 patients studied during a minor asthma exacerbation had no sputum eosinophilia. Fahy et $\mathrm{al}^{7}$ made a similar observation in patients studied during a more significant exacerbation; many patients had sputum evidence of neutrophilic airway inflammation. Subsequently non-eosinophilic asthma has been shown to be present in $25 \%$ of patients presenting to an adult respiratory clinic with symptomatic asthma, ${ }^{89}$ in patients with occupational asthma $^{10}$ and in up to $50 \%$ of patients with asthma treated with high doses of inhaled corticosteroids. ${ }^{11}$ The concept that non-eosinophilic asthma represents a pathologically distinct form of the disease is supported by work by Wenzel et al ${ }^{12}$ showing that a subgroup of patients with refractory asthma had distinctive, noneosinophilic pathology and normal basement membrane thickness on bronchial biopsy. Similar bronchial biopsy findings have been reported in patients with noneosinophilic asthma treated with inhaled $\beta_{2}$ agonists only. ${ }^{13}$ In a longitudinal study of patients with severe asthma the absence of sputum eosinophils was a stable feature over 12 months in a number of patients ${ }^{14}$; other studies indicate that non-eosinophilic pathology can be found in corticosteroid naive patients with symptoms as well as those receiving inhaled corticosteroid therapy. ${ }^{56}$ These observations suggest that, in some patients at least, non-eosinophilic asthma is a stable phenotype. Moreover, the distinctive sputum features cannot be solely due to the effects of corticosteroid therapy.

Non-eosinophilic asthma is of particular interest for several reasons. First, several uncontrolled studies have suggested that it is associated with a poor short-term response to inhaled corticosteroid therapy. ${ }^{51516}$ This has been confirmed in a recent double blind placebo controlled study. ${ }^{13}$ There is also evidence that the long-term therapeutic effects of corticosteroid therapy are disappointing: a longitudinal study has shown that patients with persistently non-eosinophilic sputum were able to substantially reduce corticosteroid therapy without any obvious increase in the frequency of asthma exacerbations over 12 months. ${ }^{14}$ A lot more work needs to be done before we can conclude that noneosinophilic asthma is a stable asthma phenotype that does not respond to corticosteroid therapy. However, there does seem to be sufficient data to raise this as a strong possibility and to suggest that noneosinophilic asthma is a clinically important entity worthy of further research.

A second point of interest is the possibility that an entirely different kind of inflammation to the TH2 driven eosinophilic airway mucosal inflammation normally associated with asthma can be associated with airway hyper-responsiveness and variable air flow obstruction. presence of increased sputum markers of neutrophilic inflammation in patients with non-eosinophilic asthma. ${ }^{9-11} 17$ Neutrophilic lower airway inflammatory responses occur in response to a wide variety of stimuli including: viral and Many investigators have highlighted the bacterial infection; chronic inflammation of structures embryologically linked to the airways ${ }^{18} 19$; and inhaled stimuli such as hypertonic saline, ${ }^{20}$ endotoxin, ${ }^{21} 22$ ozone, $^{23}$ cigarette smoke, ${ }^{24}$ other pollutants $^{25}$ and occupational irritants. ${ }^{10}{ }^{26} \mathrm{~A}$ common feature of these immune responses is the involvement of innate immunity, and Douwes et al ${ }^{17}$ have suggested that the interaction between elements of this primitive immune response and the airway might be important in the development of the airway hyper-responsiveness and variable air flow obstruction seen in non-eosinophilic asthma. Tumour necrosis factor (TNF) $\alpha$ might be particularly important in this regard as treatment with the TNF $\alpha$ antagonist etanercept has been shown to be associated with a significant improvement in airway responsiveness and air flow obstruction in patients with severe asthma. ${ }^{27}$

The concept that activation of the innate immune response in the airway occurs in non-eosinophilic asthma has been investigated in a study reported by Simpson $e a^{28}$ (see $p$ 211) in this issue of Thorax. The investigators measured expression of innate immune response receptors and cytokines, the concentration of the proinflammatory cytokine IL8 and the levels of lipopolysaccharide and endotoxin in induced sputum in patients with asthma, bronchiectasis and controls. The group with asthma were subcategorised into inflammatory phenotypes based on the induced sputum differential inflammatory cell count; all were nonsmokers. The authors found increased expression of mRNA for several innate immune response receptors and cytokines, increased IL8 and a trend to increased endotoxin concentration in induced sputum in patients who were classified as having neutrophilic asthma. Potentially pathogenic bacteria were identified in $43 \%$ of the patients with neutrophilic asthma, a finding that is in keeping with Rackemann's ${ }^{1}$ identification of a subgroup with bacterial asthma. Overall, the inflammatory profile seen in neutrophilic asthma was similar to that seen in patients with bronchiectasis, although the sputum endotoxin concentration tended to be higher and the proportion with bacterial colonisation lower in patients with neutrophilic asthma. These findings strongly support the hypothesis that activation of the innate immune response occurs in noneosinophilic asthma. The observations are cross-sectional, and it is important to investigate the effect of interventions such as bacterial eradication or removal of sources of inhaled endotoxin on the clinical and inflammatory expression of the disease before we can conclude that 
there is a direct link between these inflammatory mechanisms and airway dysfunction. The recent demonstration that treatment with telithromycin improves outcome in patients with exacerbations of asthma $^{29}$ provides some support for this view, but more studies on the role of infection in both stable and acute asthma are required before we can be sure.

One third of the patients with asthma studied by Simpson et a ${ }^{28}$ had normal sputum neutrophil and eosinophil differential cell counts. The authors suggest the term paucigranulocytic asthma for this subgroup. Whether neutrophilic and paucigranulocytic asthma can be distinguished reliably and consistently, and to what extent sputum findings reflect stable differences in the underlying lower airway immunopathology or the cause of the pathology, remains to be determined. None of the inflammatory parameters assessed in induced sputum differed between normal controls and the patients with paucigranulocytic asthma, suggesting that airway hyper-responsiveness and variable air flow obstruction can occur independently of airway inflammation as measured by induced sputum. This finding, together with evidence that the patterns of lower airway inflammatory responses associated with other airway conditions such as cough ${ }^{30-32}$ and chronic obstructive pulmonary disease ${ }^{33} 34$ are heterogeneous, implies that it might be other factors such as the intrinsic characteristics of the airway or the site of the inflammatory response ${ }^{35}{ }^{36}$ that determine the functional consequences. One key factor leading to airway hyper-responsiveness might be mast cell localisation within the airway smooth muscle as this has been observed in eosinophilic and non-eosinophilic asthma but not eosinophilic bronchitis. ${ }^{13} 35$

A final point of interest is to speculate on the consequences of the coexistence of inflammatory stimuli leading to neutrophilic airway inflammatory responses with the more usual eosinophilic inflammatory response. An elegant series of studies on smoking and asthma shows quite clearly that this combination leads to a number of features associated with more severe airway disease including: more troublesome symptoms; more frequent exacerbations; a more neutrophil dominated lower airway inflammatory response; physiological evidence of involvement of the small airways; an accelerated decline in lung function; and evidence of airway and systemic corticosteroid resistance. ${ }^{37-42}$ Importantly, many of these features improve with smoking cessation..$^{41}$ Could the effect of multiple inflammatory stimuli be an important and potentially modifiable factor leading to more severe airways disease? ${ }^{18}$ If so, then investigating the mechanisms of chronic neutrophilic airway inflammation, and the way it interacts with airway function and other airway inflammatory responses, has a wider importance.

Thorax 2007:62:193-194.

doi: 10.1136/thx.2006.065805

Correspondence to: Professor I D Pavord,

Department of Respiratory Medicine, Allergy and Thoracic Surgery, University Hospitals of Leicester NHS Trust, Glenfield Hospital, Leicester LE3 9QP, UK; ian.pavord@uhl-tr.nhs.uk

Competing interests: None declared.

\section{REFERENCES}

1 Rackemann FM. A clinical survey of 1074 patients with asthma followed for two years. J Lab Clin Med 1927; 12:1185-97.

2 Huber HL, Koessler KK. The pathology of bronchial asthma. Arch Intern Med 1922;30:689-760.

3 Diukanovic R, Roche WR, Wilson JW, et al. Mucosal inflammation in asthma. Am Rev Respir Dis 1990;142:434-57

4 Global Initiative for Asthma (GINA). Global strategy for asthma management and prevention. NHLBI/WHO Workshop report. 02-3659. Bethesda: National Institutes of Health, National Heart, Lung and Blood Institute, 2002.

5 Pavord ID, Pizzichini MM, Pizzichini E, et al. The use of induced sputum to investigate airway inflammation. Thorax 1997;52:498-501.

6 Turner MO, Hussack P, Sears MR, et al. Exacerbations of asthma without sputum eosinophilia. Thorax 1995;50:1057-61.

7 Fahy JV, Kim KW, Liu J, et al. Prominent neutrophilic inflammation in sputum from subjects with asthma exacerbation. J Allergy Clin Immunol 1995;95:843-52.

8 Pavord ID, Brightling CE, Woltmann G, et al. Non eosinophilic corticosteroid unresponsive asthma. Lancet 1999;353:2213-4.

9 Green RH, Brightling CE, Woltmann G, et al. Analysis of induced sputum in adults with asthma: identification of subgroup with isolated sputum neutrophilia and poor response to inhaled corticosteroids. Thorax 2002;57:875-9.

10 Anees W, Huggins V, Pavord ID, et al. Occupational asthma due to low molecular weight agents: eosinophilic and non-eosinophilic variants. Thorax 2002;57:231-6.

11 Gibson PG, Simpson JL, Saltos N. Heterogeneity of airway inflammation in persistent asthma: evidence of neutrophilic inflammation and increased sputum interleukin-8. Chest 2001;119:1329-36.

12 Wenzel SE, Schwartz LB, Langmack EL, et al. Evidence that severe asthma can be divided pathologically into two inflammatory subtypes with distinct physiologic and clinical characteristics. Am J Respir Crit Care Med 1999; 160:1001-8.

13 Berry MA, Morgan A, Green RH, et al. Clinical and pathological features of non-eosinophilic asthma: a distinct asthma phenotype associated with inhaled corticosteroid resistance (abstract). Thorax 2005;60:ii4

14 Green RH, Brightling CE, McKenna S, et al. Asthma exacerbations and sputum eosinophil counts: a randomised controlled trial. Lancet 2002;360:1715-21.

15 Meijer RJ, Postma DS, Kauffman HF, et al. Accuracy of eosinophils and eosinophil cationic protein to predict steroid improvement in asthma. Clin Exp Allergy 2002;32:1096-103.

16 Bacci E, Cianchetti S, Bartoli M, et al. Low sputum eosinophils predict the lack of response to beclomethasone in symptomatic asthmatic patients. Chest 2006;129:565-72.

17 Douwes J, Gibson P, Pekkanen J, et al. Noneosinophilic asthma: importance and possible mechanisms. Thorax 2002;57:643-8.
18 Pavord ID, Birring SS, Berry M, et al. Multiple inflammatory hits and the pathogenesis of severe airway disease. Eur Respir J 2006;27:884-8.

19 Birring SS, Patel RB, Parker D, et al. Airway function and markers of airway inflammation in patients with treated hypothyroidism. Thorax 2005;60:249-53

20 Pavord ID. Sputum induction to assess airway inflammation: is it an inflammatory stimulus? Thorax 1998;53:79-80.

21 Reed CE, Milton DK. Endotoxin-stimulated innate immunity: a contributing factor for asthma. J Allergy Clin Immunol 2001;108:157-66.

22 Nightingale JA, Rogers DF, Hart LA, et al. Effect of inhaled endotoxin on induced sputum in normal, atopic, and atopic asthmatic subjects. Thorax 1998:53:563-71

23 Nightingale JA, Rogers DF, Barnes PJ. Effect of inhaled ozone on exhaled nitric oxide, pulmonary function, and induced sputum in normal and asthmatic subjects. Thorax 1999;54:1061-9.

24 Kuschner WG, D'Alessandro A, Wong $\mathrm{H}$, et al. Dose-dependent cigarette smoking-related inflammatory responses in healthy adults. Eur Respir J 1996;9:1989-94

25 Nightingale JA, Maggs R, Cullinan P, et al. Airway inflammation after controlled exposure to diesel exhaust particulates. Am J Respir Crit Care Med 2000;162:161-6.

26 Clapp WD, Becker S, Quay J, et al. Grain dustinduced airflow obstruction and inflammation of the lower respiratory tract. Am J Respir Crit Care Med 1994;150:611-17.

27 Berry MA, Hargadon B, Shelley M, et al. Evidence of a role of tumor necrosis factor alpha in refractory asthma. N Engl J Med 2006;354:697-708.

28 Simpson JL, Grissell TV, Douwes J, et al. Innate immune activation in neutrophilic asthma and bronchiectasis. Thorax 2007;62:211-8.

29 Johnston SL, Blasi F, Black PN, et al. The effect of telithromycin in acute exacerbations of asthma. N Engl J Med 2006;354:1589-600.

30 Brightling CE, Ward R, Goh KL, et al. Eosinophilic bronchitis is an important cause of chronic cough. Am J Respir Crit Care Med 1999;160:406-10.

31 Birring SS, Brightling CE, Symon FA, et al. Idiopathic chronic cough: association with organ specific autoimmune disease and bronchoalveolar lymphocytosis. Thorax 2003;58:1066-70.

32 Jatakanon A, Lalloo UG, Lim S, et al. Increased neutrophils and cytokines, TNF-alpha and IL-8, in induced sputum of non-asthmatic patients with chronic dry cough. Thorax 1999;54:234-7.

33 Brightling CE, Monteiro W, Ward R, et al. Sputum eosinophilia and short-term response to prednisolone in chronic obstructive pulmonary disease: a randomised controlled trial. Lancet 2000;356: 1480-5

34 Birring SS, Brightling CE, Bradding $P$, et al. Clinical radiologic, and induced sputum features of chronic obstructive pulmonary disease in nonsmokers: a descriptive study. Am J Respir Crit Care Med 2002;166:1078-83.

35 Brightling CE, Bradding P, Symon FA, et al. Mastcell infiltration of airway smooth muscle in asthma. N Engl J Med 2002;346:1699-705.

36 Brightling CE, Pavord ID. Location, location, location: microlocalisation of inflammatory cells and airway dysfunction. Thorax 2004;59:734-5.

37 Thomson NC, Spears M. The influence of smoking on the treatment response in patients with asthma. Curr Opin Allergy Clin Immunol 2005;5:57-63.

38 Thomson NC, Chaudhuri R, Livingston E. Asthma and cigarette smoking. Eur Respir 2004; 24:822-33.

39 Chaudhuri R, Livingston $E$, McMahon $A D$, et al. Cigarette smoking impairs the therapeutic response to oral corticosteroids in chronic asthma. Am J Respir Crit Care Med 2003;168:1308-11.

40 Chaudhuri $R$, Livingston $E$, McMahon $A D$, et al. Effects of smoking cessation on lung function and airway inflammation in smokers with asthma. Am J Respir Crit Care Med 2006;174:127-33.

41 Lange P, Parner J, Vestbo J, et al. A 15-year followup study of ventilatory function in adults with asthma. N Engl J Med 1998;339:1 194-200.

42 Antic R, Macklem PT. The influence of clinical factors on site of airway obstruction in asthma. Am Rev Respir Dis 1976;114:851-9. 